\title{
The usefulness of laboratory and radiological investigations in the management of Supraventricular Tachycardia
}

(Running Title: Supraventricular tachycardia investigations)

Aadith Ashok BBMed MD

Alfred Hospital, Prahran, Victoria, Australia

aadithashok7@gmail.com

Miguel Cabalag MBBS BMedSci PGDipSurgAnat

Department of Surgery, Austin Hospital, Heidelberg, Victoria, Australia

miguel.cabalag@gmail.com

David McD. Taylor MBBS MD MPH DRCOG FACEM

Emergency Department, Austin Hospital, Heidelberg, Victoria, Australia

Department of Medicine, University of Melbourne, Parkville, Victoria, Australia

David.Taylor@austin.org.au

\section{Author contributions}

All authors conceived and designed the study. DT supervised the conduct of the study and data collection. AA and MC undertook all data collection. DT analyzed the data. All authors drafted the manuscript and contributed substantially to its revision. DT takes responsibility for the paper as a whole.

\section{Address for Correspondence:}

Professor David Taylor

Emergency Department, Austin Hospital,

Studley Road, Heidelberg, Victoria, Australia 3084

Phone (W) +61 394964711

David.Taylor@austin.org.au

Word count: Abstract 250, Text 2,308

\section{Funding Sources}

The project was unfunded

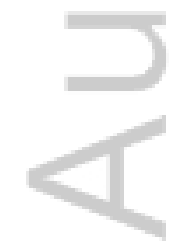

This is the author manuscript accepted for publication and has undergone full peer review but has not been through the copyediting, typesetting, pagination and proofreading process, which may lead to differences between this version and the Version of Record. Please cite this article as doi: $10.1111 / 1742-6723.12766$ 


\begin{abstract}
Objective

Although Emergency Department (ED) patients presenting with supraventricular tachycardia (SVT) are commonly investigated, the value of these investigations has been questioned. We aimed to determine the frequency and utility of investigations in patients with SVT.
\end{abstract}

\title{
Methods
}

We undertook an explicit retrospective medical record audit of patients with SVT who presented to a single ED (January 2004 - June 2014). Data on demographics, presenting complaints, investigations and outcomes were extracted. The outcomes were nature and utility of investigations.

\section{Results}

633 patients were enrolled (mean [SD] age 55.4 [17.7] years, $62 \%$ female).

Laboratory investigations were common: electrolytes ( $83.7 \%$ of patients), full blood count (81.2\%), magnesium (57.5\%), calcium (39.3\%) and thyroid function $(30.3 \%)$.

These investigations revealed many mildly abnormal results but resulted in electrolyte supplementation in only 19 patients: 8 with mild hypokalaemia (potassium 3.03.5mmol/L) and 11 with mild hypomagnesia (magnesium 0.49-1.1 mmol/L).

Troponin was ordered for 302 (47.7\%) patients, many of whom had no history or risk factors for cardiac disease, or ischaemic symptoms associated with their SVT. The troponin was normal, mildly and moderately elevated in $65.2 \%, 24.5 \%$ and $10.2 \%$ of cases, respectively. Only 7 (1.1\%) patients were diagnosed with myocardial infarction. Although 190 (30.0\%) patients had a chest X-ray, it was normal in 78.4\% of cases. All chest X-ray abnormalities were incidental and not relevant to the immediate ED management. 


\section{Conclusion}

Patients with uncomplicated SVT are over-investigated. Guidelines for ED SVT investigation are recommended. Further research is recommended to determine the indications for each investigation in the setting of SVT.

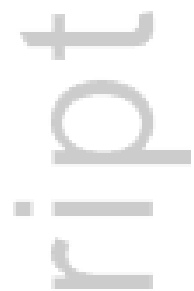

\section{Keywords}

Supraventricular tachycardia, emergency department, investigation, electrolytes, troponin
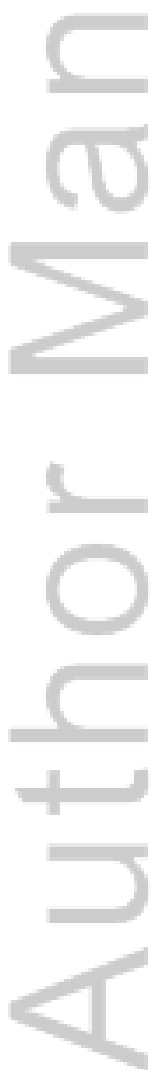

This article is protected by copyright. All rights reserved. 


\section{INTRODUCTION}

Supraventricular tachycardia (SVT) is a relatively common presentation to the emergency department (ED) with most cases due to either atrio-ventricular (AV) nodal re-entry or AV re-entry. ${ }^{1}$ It is usually a benign condition that is easily managed. $^{2-4}$

Patients with SVT tend to be reasonably young with a mean age of less than 60 years. ${ }^{1,5-7}$ Accordingly, relatively few have known ischaemic heart disease (IHD) or other cardiac related co-morbidities. ${ }^{1,6}$ Furthermore, although SVT is a cardiac condition, it does not necessarily mean that these patients are more likely to have other cardiac disease.

In the absence of evidence-based guidelines for the investigation of these patients in the ED, it is not surprising that some clinicians default to investigations appropriate for patients with acute coronary syndrome. In addition to an ECG, laboratory and radiological investigations are frequently undertaken. Despite this being common practice, there is limited evidence for their usefulness in the ED setting.

We aimed to determine the nature, frequency and utility of laboratory and radiological investigations ordered for patients who present to the ED for treatment of SVT. The findings will inform the development of clinical guidelines for the rational use of investigations for this condition in the ED setting. 


\section{METHODS}

\section{Study Design and Setting}

We undertook a retrospective observational study of consecutive cases of SVT who presented to a single ED over a 10 year period (January 2004 - January 2014 inclusive). The ED is situated within a tertiary referral public hospital and has an average annual census of approximately 77,000 patients. The hospital's Human Research Ethics Committee approved the project.

\section{Study Population}

Potential cases were identified from the ED patient tracking system, MedTrak ${ }^{\mathrm{TM}}$. The database was searched for all cases with a discharge diagnosis of 'Paroxysmal Supraventricular Tachycardia' (ICD-10-CM I47.1). For cases who presented prior to December 2009, their hardcopy medical records were reviewed. All other records were reviewed electronically.

Patients were included in the study if they were aged 18 years or more and had presented for treatment of SVT. Patients with any other arrhythmia were excluded.

\section{Study Protocol}

Explicit data extraction from the patient medical records was undertaken by two investigators (AA, MC). All data were entered onto a hard copy data collection document and subsequently into the project electronic database. A third investigator (DT) reviewed the records of a random sample of $5 \%$ of patients and verified the 
accuracy of the data extraction procedure. All investigators reviewed the patient ECGs to confirm that the rhythm was consistent with SVT.

The data included patient demographics, past medical history, medications (regular and treatment), duration of the SVT and associated symptoms, and place of disposition. The nature and results of investigations undertaken were extracted from either the medical record or pathology and radiology databases.

\section{Key Outcomes}

The primary study outcome was the nature of the laboratory and radiological investigations undertaken. Secondary outcomes were the proportions of investigations that were abnormal and the impact that these investigations had upon patient management.

\section{Data Analysis}

No formal sample size calculation was undertaken. All cases meeting the study entrance criteria were enrolled. The lengthy study period was thought to be adequate to generate preliminary data that may indicate the need for further investigation. A post hoc power analysis indicated that the study had a power of 0.99 to demonstrate a difference in troponin testing rates between patients who did/did not have IHD (ratio 1:10, 2-sided, alpha 0.05).

Most data were analysed descriptively. Point estimates (percentages, means, medians) were calculated and fitted with 95\% confidence intervals, standard deviations (SD) or inter-quartile range (IQR) where appropriate. The Chi square test was employed for 
comparison of proportions. Statistical analyses were undertaken using SPSS for

Windows statistical software (version 22.0), SPSS Inc., Chicago, Illinois, USA. The level of significance was 0.05 .

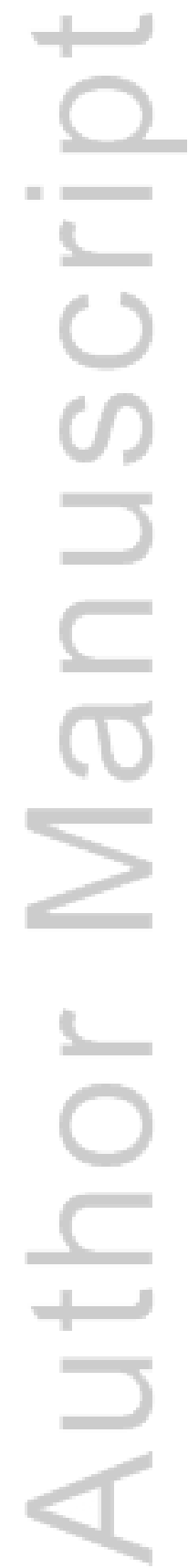

This article is protected by copyright. All rights reserved. 


\section{RESULTS}

Screening of the ED tracking system identified 822 potential cases. Of these, 175 and 14 were excluded for a true discharge diagnosis other than SVT and incomplete documentation, respectively. The remaining 633 patients were enrolled.

The patient characteristics are presented in Table 1 . The majority were middle-aged and female. More than one half had a history of SVT. Although more than one third had risk factors for cardiovascular (CV) disease, only a small proportion had known IHD.

The investigations ordered, their results and the numbers of patients treated as a result of the investigations are reported in Table 2 . The large majority $(>80 \%)$ of patients had full blood counts and electrolytes levels measured. Approximately one half had magnesium, calcium and troponin levels measured and one fifth had a thyroid function test.

For most laboratory tests, the results were within the normal ranges in at least $80 \%$ of cases. Most abnormal results were only marginally outside the normal range. Only the potassium and magnesium results altered ED management. Four patients with normal/marginally low potassium levels and four patients with moderately low levels were administered $10 \mathrm{mmol}$ intravenous potassium. Fourteen patients were administered 20mmol intravenous $\mathrm{MgSO} 4$ including eight with normal/marginally elevated levels and three who did not have a magnesium level measured. 
Almost one third of patients had a chest X-ray (Table 2) and approximately one fifth of X-rays were reported as having an abnormality. However, none was thought to be related to the SVT event and none required further management.

Approximately one quarter and one tenth of troponin levels were mildly or moderately elevated, respectively. Troponin testing varied according to the patients' medical history (Table 3). Similar proportions of patients with no CV risk factors or IHD were tested compared to patients with CV risk factors. Also, the results of the troponin tests were similar. However, patients with known IHD disease were tested significantly more often than patients who did not: $76.4 \%$ versus $44.2 \%$ (difference $32.2 \%, 95 \%$ CI $19.2,45.1, \mathrm{p}<0.001)$. Patients with known IHD were slightly more likely to have an abnormal troponin result: $64.2 \%$ versus $47.7 \%$ (difference $16.6 \%$, $95 \% \mathrm{CI}-1.0,34.9, \mathrm{p}=0.06)$.

Nearly all patients $(582,91.9 \%)$ reported palpitations associated with their SVT.

Other common associated symptoms included chest pain, dyspnoea and pre-syncope (Table 3). Troponin testing varied according to the presence of associated symptoms. Patients with at least one associated symptom were tested significantly more often than patients who did not: $57.6 \%$ versus $28.2 \%$ (difference $29.4 \%$, 95\% CI $21.4,37.5$, $\mathrm{p}<0.001)$. Also, patients with associated symptom(s) were significantly more likely to have an abnormal troponin result: $78.3 \%$ versus $62.0 \%$ (difference $16.3 \%, 95 \% \mathrm{CI} 3.2$, $29.5, \mathrm{p}=0.02)$.

Patient disposition was associated with the troponin results. Sixty five (33.0\%), 51 $(68.9 \%)$ and $23(74.2 \%)$ of patients with normal, mildly elevated or moderately 
elevated troponin levels were admitted to the hospital, respectively $(p<0.001)$. Only $31(9.4 \%)$ of patients who did not have a troponin test were admitted.

Seven patients were ultimately diagnosed with acute myocardial infarction (AMI). Their mean age was 68.3 years, five were male, all had CV risk factors and four had known IHD. Three, one and three patients had normal, mildly elevated and moderately elevated troponin levels, respectively.

This article is protected by copyright. All rights reserved. 


\section{DISCUSSION}

The large majority of our patients had laboratory investigations undertaken. However, in almost all cases, the results were normal or near normal and did not change ED management.

\section{Full blood and electrolyte investigations}

Anaemia can induce arrhythmias including SVT. ${ }^{3,8,9}$ In our study, only two patients had very low haemoglobin counts and neither was treated for anaemia during their ED stay. For these patients, there was no documentation of any clinical signs of anaemia or other anaemia-related symptoms.

Hypo/hyperkalaemia and hypomagnesaemia have been reported to induce arrhythmias due to their effects on cardiac contractility and the cardiac action potentials. However, these effects are strongest in the precipitation of ventricular dysrhythmias and atrial fibrillation. ${ }^{10-13}$

To date, there is no evidence that electrolyte abnormalities among ED patients are associated with SVT or that correction of these abnormalities is of benefit. Despite this, potassium supplementation was administered to eight patients. Of particular concern is that four of these patients had normal or marginally low potassium levels. Given the retrospective nature of this study, the rationale for treating the patients with electrolyte supplements cannot be determined.

Magnesium sulphate is administered to post-pneumonectomy patients to prevent and help in the treatment of arrhythmias including SVT. ${ }^{14}$ However, no study to date has 
investigated the impact of magnesium supplementation in patients presenting to the ED with SVT. Of the fourteen patients treated with magnesium supplementation in our study, only two had low magnesium levels. Furthermore, three patients were treated without a magnesium level being measured.

Almost one fifth of patients in our study had thyroid function measured in the ED and no case had severe thyroid dysfunction. Hyperthyroidism is associated with the precipitation of atrial fibrillation and thyroid function testing has been recommended for patients with arrhythmia. ${ }^{2}$ However, there is no evidence that thyroid dysfunction is associated with SVT. Despite this, Sawhney et al. ${ }^{7}$ reported that $65 \%$ of patients with SVT had thyroid function measured in the ED, as recommended by the UK National Service Framework guidelines.

\section{Troponin levels}

Troponin levels were measured in almost one half of patients and often in those with no risk factors for IHD and/or those with no associated symptoms. This is despite little association between SVT and IHD. ${ }^{15-17}$ Dorenkamp et al. ${ }^{17}$ evaluated 114 patients presenting with SVT for concomitant IHD. Although many had features suggestive of myocardial ischemia (e.g. chest pain and elevated troponin), the prevalence of significant IHD on coronary angiography was low (4\%) and did not correlate with associated symptoms during the SVT. The reason for the high rate of troponin measurement in our study is not known but may relate to the reflex ordering of a cardiac panel of tests in the absence of an evidence-based guideline. 
Troponin is specific for myocardial injury, which is not always caused by myocardial ischaemia. Non-ischaemic myocardial injury may be caused by pulmonary embolus, heart failure, pericardial disease and arrhythmia. ${ }^{16,18}$ There are a number of reports of elevated troponin levels in patients with SVT and these elevations were thought to be rate-related rather than ischaemic in nature..$^{5,15,16,18,19}$ It was not surprising, therefore, that the troponin was elevated in approximately one third of our patients in whom it was measured. Importantly, an elevated troponin in patients with SVT does not necessarily predict adverse events or poor outcomes. ${ }^{15,20}$

Few patients in our study were diagnosed with AMI and some of these had normal troponin levels. This finding is consistent with reports that troponin levels are poor predictors of AMI in the setting of SVT. ${ }^{15,16,18,20}$ Troponin measurement, therefore, may have limited usefulness in the investigation of patients with SVT. Our finding that troponin was measured more often in patients with a history of IHD and/or in those with associated symptoms appears reasonable. However, the place for troponin testing in this setting is not well defined and needs further investigation.

Most patients with SVT can be safely discharged from the ED after a short period of observation. ${ }^{1,6}$ In our study, a considerable proportion of patients were discharged home despite having an elevated troponin. It is not known if these patients experienced an adverse event after discharge as follow up data were not collected.

\section{Chest Xray results}

Although a number of abnormalities were found on chest X-rays, none resulted in a change of ED management. For patients with SVT, this investigation appears to have 
limited value in the ED. Depending upon the level of suspicion of chest pathology, a venous blood gas measurement may offer a simple screening test. It has been recommended, however, that patients should be referred for outpatient echocardiogram to identify structural diseases that have strong associations with SVT. ${ }^{2,4,21}$

\section{Implications}

The findings of this study suggest that substantial time and resource could be saved if the investigation of patients with SVT is rationalised. This would be consistent with the Choosing Wisely Australia ${ }^{\circledR}$ initiative which aims to improve the quality of healthcare by eliminating, among other things, unnecessary and sometimes harmful investigations. $^{22}$

\section{Limitations}

This study has strengths and limitations. Some patients may have been missed during the patients tracking system search if they had been incorrectly coded. However, the discharge diagnosis code was used only to screen for potential patients and all ECGs were reviewed prior to enrolment.

Our patient cohort is likely to be representative of patients with SVT. Others have also reported that these patients are predominantly female ${ }^{1}$, middle aged ${ }^{1,6}$, usually do not have associated co-morbidities ${ }^{6}$ and complain mostly of palpitations and often chest pain ${ }^{1,23}$. 
The retrospective study design may have introduced measurement bias. Data in the medical record may have been missing, incomplete or ambiguous. However, the data accuracy exercise indicated that data were extracted accurately.

As a single centre study, the external validity of the findings may be limited.

However, the large sample size and the long enrolment period mean that the findings are likely to reflect the practice of a large number of clinicians.

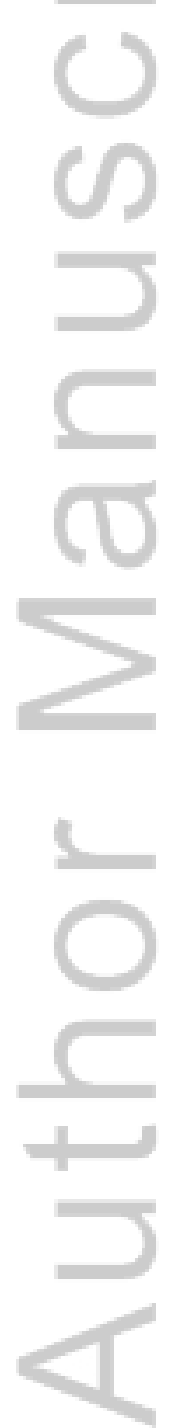

This article is protected by copyright. All rights reserved. 


\section{CONCLUSION}

Patients with uncomplicated SVT are over-investigated. While most patients have laboratory and/or radiological investigations undertaken, the results are normal or near normal in the large majority of cases and rarely provide a rational basis for a change in ED management. Such investigation practice has implications for the costs of patient management and the time that patients spend in the ED. While troponin levels are frequently elevated this is likely to be rate-related and troponin is a poor predictor of AMI in this setting. Many patients with elevated troponin levels were discharged home and patients ultimately diagnosed with AMI may or may not have had an elevated level. Troponin measurement should be guided by the level of clinical suspicion of the treating clinician. With the exception of troponin measurement, no significant pathology would have been missed if no investigations had been undertaken. Further research is recommended to determine the indications for each investigation. Guidelines are needed to rationalise the use of investigations by limiting them to those with specific indications and for whom the results are likely to affect a change in ED management.

This article is protected by copyright. All rights reserved. 


\section{REFERENCES}

1. Murman DH, McDonald AJ, Pelletier AJ, Camargo CA, Jr. U.S. emergency department visits for supraventricular tachycardia, 1993-2003. Acad Emerg Med $2007 ; 14: 578-581$

2. Blomstrom-Lundqvist C, Scheinman M, Aliot E, Alpert J, Calkins H, Camm AJ, et al. ACC/AHA/ESC guidelines for the management of patients with supraventricular arrhythmias - executive summary. J Am College Cardiol. 2003;42:1493-1531

3. Medi C, Kalman JM, Freedman SB. Supraventricular tachycardia. MJA $2009 ; 190: 255-260$

4. Whinnett Z, Sohaib SMA, Davies DW. Diagnosis and management of supraventricular tachycardia. BMJ 2012;345:e7769

5. Bukkapatnam RN, Robinson M, Turnipseed S, Tancredi D, Amsterdam E, Srivatsa UN. Relationship of myocardial ischemia and injury to coronary artery disease in patients with supraventricular tachycardia. Am J Cardiol 2010;106:374-377

6. Luber S, Brady WJ, Joyce T, Perron AD. Paroxysmal supraventricular tachycardia: outcome after ED care. Am J Emerg Med 2001;19:40-42

7. Sawhney V, Corden B, Abdul-Mukith K, Harris T, Schilling RJ. Are patients admitted to emergency departments with regular supraventricular tachycardia (SVT) treated appropriately? Clin Med 2013;13:146-148

8. Fox DJ, Tischenko A, Krahn AD, Skanes AC, Gula LJ, Yee RK, et al. Supraventricular tachycardia: diagnosis and management. Mayo Clin Proc. $2008 ; 83: 1400-1411$ 
9. O'Rourke SF, Sauvage A, Evans PA. Paroxysmal supraventricular tachycardia: improving diagnosis and management within the accident and emergency department. EMJ 2004;21:495-497

10. Dyckner T. Relation of cardiovascular disease to potassium and magnesium deficiencies. Am J Cardiol 1990;65:44-46K

11. Kolte D, Vijayaraghavan K, Khera S, Sica DA, Frishman WH. Role of magnesium in cardiovascular diseases. Cardiol Rev 2014;22:182-192

12. Millane TA, Ward DE, Camm AJ. Is hypomagnesemia arrhythmogenic? Clin Cardiol 1992;15:103-108

13. Maciejewski P, Bednarz B, Chamiec T, Górecki A. Acute coronary syndrome: potassium, magnesium and cardiac arrhythmia. Kardiologia Polska 2003;59:402-407 14. Kotoulas C, Konstantinou G, Kostikas K, Doris M, Konstantinou M, Prendergast $\mathrm{B}$, et al. Are the perioperative changes of serum magnesium in lung surgery arrhythmiogenic? J Balkan Union Oncol 2006;11:69-73 15. Schueler M, Vafaie M, Becker R, Biener M, Thomas D, Mueller M, et al. Prevalence, kinetic changes and possible reasons of elevated cardiac troponin $\mathrm{T}$ in patients with AV nodal re-entrant tachycardia. Acute Cardiac Care. 2012;14:131-137 16. Ben Yedder N, Roux JF, Paredes FA. Troponin elevation in supraventricular tachycardia: primary dependence on heart rate. Canad J Cardiol 2011;27:105-109 17. Dorenkamp M, Zabel M, Sticherling C. Role of coronary angiography before radiofrequency ablation in patients presenting with paroxysmal supraventricular tachycardia. J Cardiovasc Pharmacol Ther 2007;12:137-144.

18. Healey JS. Troponin elevation in patients with supraventricular tachycardia: what does it mean? Canad J Cardiol 2011;2:110-111 
19. Chow GV, Hirsch GA, Spragg DD, Cai JX, Cheng A, Ziegelstein RC, et al. Prognostic significance of cardiac troponin I levels in hospitalized patients presenting with supraventricular tachycardia. Medicine 2010;89:141-148

20. Carlberg DJ, Tsuchitani S, Barlotta KS, Brady WJ. Serum troponin testing in patients with paroxysmal supraventricular tachycardia: outcome after ED care. Am J Emerg Med 2011;29:545-48

21. Alpert MA, Hashimi MW, Concannon MD, Bikkina M, Mukerji V. Pathogenesis, recognition, and management of common cardiac arrhythmias. Part II:

Supraventricular premature beats and tachyarrhythmias. Southern Med J $1995 ; 88: 153-174$

22. National Prescribing Service MedicineWise. Choosing Wisely Australia.

Available at http://www.choosingwisely.org.au/home (last accessed Decembr 19, 2016)

23. Wood KA, Drew BJ, Scheinman MM. Frequency of disabling symptoms in supraventricular tachycardia. Am J Cardiol 1997;79:145-149

\section{Acknowledgements}

None. The authors declare no conflicts of interest

This article is protected by copyright. All rights reserved. 
Table 1. Patient characteristics and disposition $(n=633)$

\begin{tabular}{|c|c|c|}
\hline Characteristic & $\mathrm{n}$ & $(\%)$ \\
\hline Age, years, mean (SD) & 55.4 & $(17.7)$ \\
\hline Female & 394 & $(62.2)$ \\
\hline \multicolumn{3}{|l|}{ Past history } \\
\hline SVT & 349 & $(55.1)$ \\
\hline Cardiovascular disease risk factors ${ }^{\dagger}$ & 195 & $(30.8)$ \\
\hline Ischaemic heart disease & 55 & $(8.7)$ \\
\hline SVT duration at presentation, minutes, median (IQR) & 90 & $(45,162.5)$ \\
\hline \multicolumn{3}{|l|}{ Disposition } \\
\hline Home & 439 & $(69.4)$ \\
\hline Short Stay Unit & 124 & $(19.6)$ \\
\hline Ward & 50 & $(7.9)$ \\
\hline Coronary Care / Intensive Care Unit & 18 & $(2.8)$ \\
\hline Other & 2 & $(0.3)$ \\
\hline
\end{tabular}

${ }^{\dagger}$ hypertension, dyslipidaemia, vascular disease, diabetes, cardiac failure

${ }^{\ddagger}$ discharged to a subacute hospital and to a private hospital

This article is protected by copyright. All rights reserved. 
Table 2. Investigations ordered, results and treatment given

\begin{tabular}{|c|c|c|c|c|}
\hline $\begin{array}{l}\text { investigation } \\
\text { no. patients where test ordered (\%) }\end{array}$ & result range & & $(\%)$ & $\begin{array}{c}\mathrm{n} \\
\text { treated }\end{array}$ \\
\hline Haemoglobin $(\mathrm{g} / \mathrm{L}), 514(81.2 \%)$ & $60-79$ & 2 & $(0.4)$ & 0 \\
\hline & $80-109$ & 27 & $(5.4)$ & 0 \\
\hline & $110-119$ & 22 & $(4.3)$ & 0 \\
\hline & $120-165$ (normal) & 457 & $(88.8)$ & 0 \\
\hline & $>165$ & 6 & $(1.2)$ & 0 \\
\hline White cell count $\left(10^{9} / \mathrm{L}\right), 514(81.2 \%)$ & $<4.0$ & 14 & $(2.7)$ & 0 \\
\hline$=$ & $4.0-11.0$ (normal) & 402 & $(78.2)$ & 0 \\
\hline & $>11.0$ & 98 & $(19.1)$ & 0 \\
\hline Sodium (mmol/L), $530(83.7 \%)$ & $126-135$ & 27 & $(5.1)$ & 0 \\
\hline & 136-145 (normal) & 495 & $(93.4)$ & 0 \\
\hline & $>150$ & 8 & $(1.5)$ & 0 \\
\hline Potassium (mmol/L), 530 (83.7\%) & $>5.1$ & 11 & $(2.1)$ & 0 \\
\hline & 3.5-5.1 (normal) & 484 & $(91.3)$ & 1 \\
\hline & 3.4 & 17 & $(3.2)$ & 3 \\
\hline & $3.0-3.3$ & 18 & $(3.4)$ & 4 \\
\hline Chloride (mmol/L), $530(83.7 \%)$ & $<98$ & 27 & $(5.0)$ & 0 \\
\hline & 98-107 (normal) & 477 & $(90.0)$ & 0 \\
\hline & $>107$ & 26 & $(5.0)$ & 0 \\
\hline Magnesium (mmol/L), 364 (57.5\%) & not ordered & 269 & $(42.5)$ & 3 \\
\hline & ordered, level unknown & 140 & $(38.5)$ & 1 \\
\hline & $<0.49$ & 1 & $(0.3)$ & 1 \\
\hline & $0.50-0.65$ & 10 & $(2.7)$ & 1 \\
\hline & $0.66-1.00$ (normal) & 183 & $(50.3)$ & 6 \\
\hline & $1.01-1.10$ & 26 & $(7.1)$ & 2 \\
\hline & $>1.10$ & 4 & $(1.1)$ & 0 \\
\hline Calcium (mmol/L), 249 (39.3\%) & $<2.15$ & 2 & $(0.8)$ & 0 \\
\hline & $2.15-2.55$ (normal) & 242 & $(97.2)$ & 0 \\
\hline & $>2.55$ & 5 & $(2.0)$ & 0 \\
\hline & $<0.27$ & 8 & $(7.0)$ & 0 \\
\hline$(\mathrm{mU} / \mathrm{L}), 114(18.0 \%)$ & $0.27-4.2$ (normal) & 98 & $(86.0)$ & 0 \\
\hline & $>4.2$ & 8 & $(7.0)$ & 0 \\
\hline Troponin (ng/L), 302 (47.7\%) & normal & 197 & $(65.2)$ & - \\
\hline & minor elevation $^{\ddagger}$ & 74 & $(24.5)$ & - \\
\hline & moderate elevation ${ }^{\ddagger}$ & 31 & $(10.3)$ & - \\
\hline Chest X-ray, $190(30.0 \%)$ & normal & 149 & $(78.4)$ & 0 \\
\hline & abnormal $^{\S}$ & 41 & $(21.6)$ & 0 \\
\hline
\end{tabular}

${ }^{\dagger} \mathrm{TSH}$ thyroid stimulating hormone

${ }^{\ddagger}$ minor elevation: $0.14<$ hsTrop $<0.50,0.02<\mathrm{cTrop}<0.2$; moderate elevation: hsTrop $>0.50$, cTrop $>0.2$

$\S$ cardiomegaly (14 cases), pulmonary oedema (14), restrictive disease (5), pneumonia (4), vertebral degeneration (4), pleural effusion (3), atelectasis (3), pulmonary lesions (3), pulmonary hypertension (2), obstructive lung disease (2), pericardial disease (1), apical bleb (1) (12 patients had $>1$ abnormality) 
Table 3. Relationship between medical history and symptoms, and first troponin results

troponin result

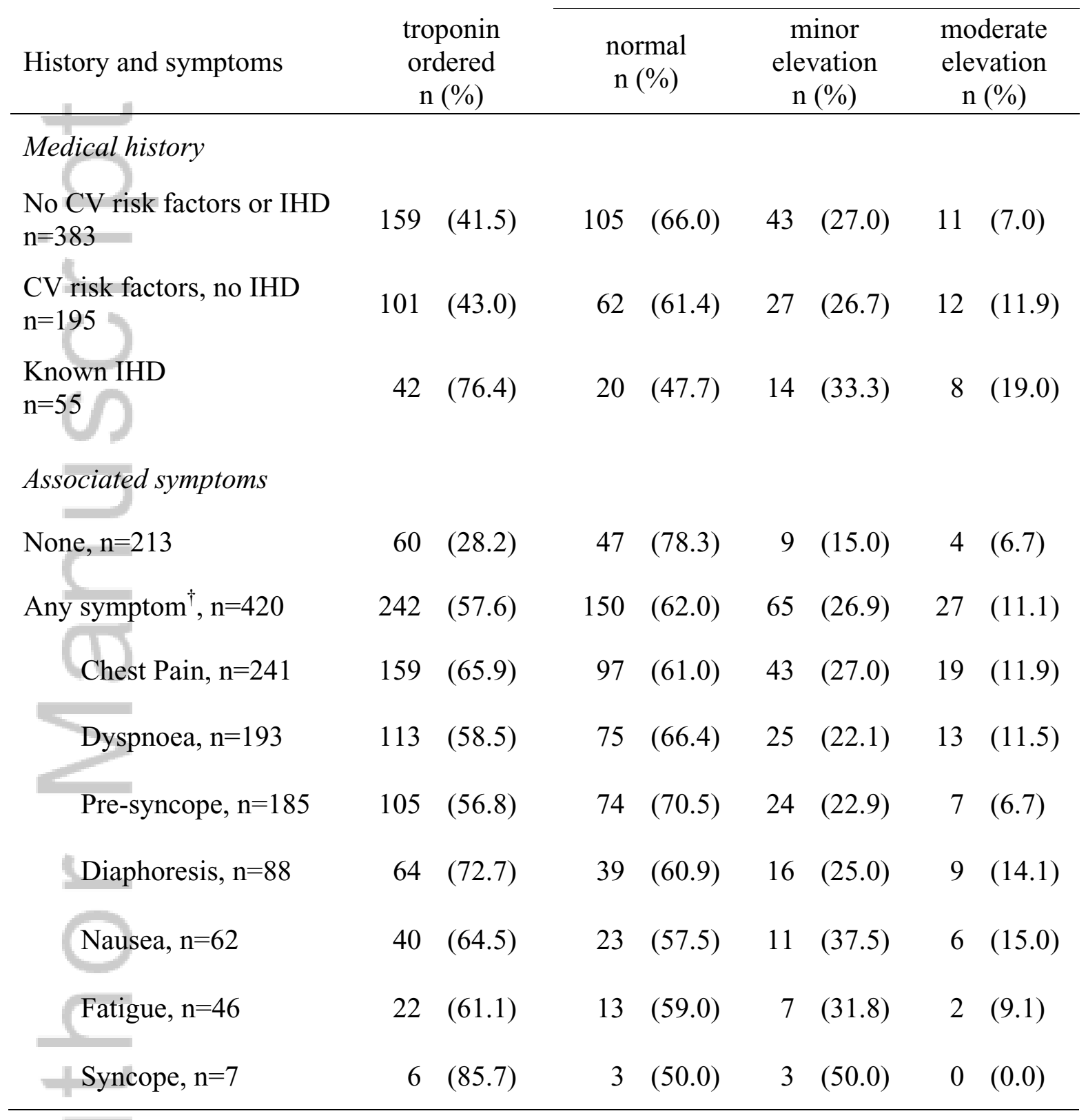

${ }^{\dagger}$ groups not mutually exclusive, patients may have had one or more symptoms

CV cardiovascular, IHD ischaemic heart disease 


\section{University Library}

\section{- M M N E R VA A gateway to Melbourne's research publications}

Minerva Access is the Institutional Repository of The University of Melbourne

Author/s:

Ashok, A;Cabalag, M;McD Taylor, D

Title:

Usefulness of laboratory and radiological investigations in the management of supraventricular tachycardia

Date:

2017-08-01

Citation:

Ashok, A., Cabalag, M. \& McD Taylor, D. (2017). Usefulness of laboratory and radiological investigations in the management of supraventricular tachycardia. EMERGENCY MEDICINE AUSTRALASIA, 29 (4), pp.394-399. https://doi.org/10.1111/1742-6723.12766.

Persistent Link:

http://hdl.handle.net/11343/292671 